\title{
Tuning of PID Controller for Realistic Load Frequency Control System using Chaotic Exponential PSO Algorithm
}

\author{
Santigopal Pain ${ }^{\# 1}$, Parimal Acharjee ${ }^{* 2}$ \\ \# Department of Applied Electronics and Instrumentation Engineering, \\ Dr. B. C. Roy Engineering College, Durgapur, 713206, India \\ 1 pain.santigopal@gmail.com \\ * Department of Electrical Engineering, National Institute of Technology, Durgapur, 713209, India \\ ${ }^{2}$ parimal.acharjee@gmail.com
}

\begin{abstract}
For a realistic multi-area interconnected power system model with different generating units (reheat, non-reheat and hydro generating units) and real time different system parameters, design and analysis of load frequency control (LFC) are executed using new and unique chaotic exponential PSO (CHEPSO) algorithm. Considering both transient and steady-state specifications with proper weighting factors, four objective functions are formulated for practical LFC model with nonlinear security constraints such as generation rate constraint (GRC), governor dead band (GDB) and time delay. In the context of reliable convergence, multiple solutions, improvement of both transient and steady state performances, the performance of the proposed CHEPSO technique is compared with other techniques like real-coded genetic algorithm (RCGA), general PSO (GPSO) and exponential PSO (EPSO) techniques. The proposed technique gives the best performances for all cases.
\end{abstract}

Keyword - Chaotic local search, Chaotic exponential particle swarm optimization, Security constraints, Realistic LFC system, Multiple solutions

\section{INTRODUCTION}

The dynamic of the power system changes due to load variation, disturbances and/or changing operating conditions. This leads to abrupt changes in frequency and inter area tie line power which make the power system most unreliable and unstable. Hence, the frequency and voltage profile of the power system will deviate from the normal operating condition. For successful operation under abnormal condition, the mismatch between generation and demand has to be corrected by applying suitable control strategy. Load frequency control (LFC) is an effective mechanism in power system operation and control for minimizing the mismatches and supplying good quality of electric power with sufficient reliability [1]. The primary objectives of the LFC are maintaining the frequency and tie line power at schedule values, improving the power system performance by making zero steady state error $(S S E)$, minimum overshoot $\left(M_{p}\right)$ and minimum settling time $\left(t_{s}\right)$.

Over the years, several control strategies had been successfully used to address the LFC design problems in order to improve the dynamic performance of the power system. Among the various controller used so far, the most widely used controller is the conventional proportional integral (PI) controller [1]. Though it has simple structure and easy implementation, it is failed to achieve the expected result for large scale interconnected power system. Therefore, a lot of control design approaches based on modern control theory like decentralized robust, adaptive and optimal control methods had been employed to LFC design [2]-[6]. All the above mentioned conventional control methodologies are model specific and designed for specific type of disturbances. Moreover, the order of the controllers becomes high as that of the plant. The dynamic of the power system is highly nonlinear. The nonlinearities present in the system are generation rate constraint (GRC), governor dead band (GDB) and time delay. The complexity of the power system is increased due to large structure, nonlinearities present in the system, abrupt load variation, parameter uncertainty, changing operating condition etc. The model based controller that perform better for specific model and disturbance are unable to solve LFC problem for such complex power system. Therefore, the design of soft computing based intelligent controllers which are more adaptive than linear and robust/optimal controller had been employed. The fuzzy logic control on its different form was successfully applied to design/cater LFC and other control engineering problems and is reported in [7]-[9]. The GA is powerful search optimization technique that was conveniently used for tuning LFC parameters [10-13]. Another popular technique, PSO was widely used to solve the complex power system problems [14]-[17]. The performance of the PSO was enhanced by introducing adaptive inertia weight $(w)$ and is reported in [18], [19]. However, PSO sometimes fails to reach the global minimum due to poor diversity and stick to the local minima. To overcome this problem, chaos is introduced with PSO and a powerful tool CPSO was developed and effectively utilized for optimization problems [20]-[22]. Recently, several other evolutionary computation techniques and their hybrid forms like, Artificial Bee Colony Optimization (ABCO), Teaching 
Learning Based Optimization (TLBO), Ant Lion Optimizer Algorithm, BAT algorithm, Hybridized Disruption based Opposition Learned Gravitational Search Algorithm (DOGSA), hybrid bacteria foraging optimization algorithm-pattern search (BFOA-PS) algorithm, fire fly-pattern search (FF-PS) algorithm [23]-[29], to name a few, which were effectively used to design LFC problems with or without constraint scenario. In most of the above mentioned soft computing based literatures, LFC design were carried out by taking simple linear model with identical power generating units for all the connected areas. The similar values of parameters for all the generating units of different control areas were considered for simplicity and easy implementation. But this is not practical. Moreover, in most of the articles, the important physical security constraints like GRC, GDB and time delay were neglected partly or by full during designing of the LFC system. These design approaches may face difficulty during practical implementation. To get an accurate design of the LFC system, the connected generating units of different control areas must be of different type with different parameter values and the physical security constraints must be considered.

In LFC design, consideration of all the limitations may be of difficult task but it is very useful to get accurate dynamic behavior of the power system. The physical constraints affect the transient as well as steady state behavior of the system by increasing $M_{p}, t_{s}, S S E$ and also degrade the stability of the system. So, designing the controller without considering these constraints will degrade the performance of the designed controller and the overall performance of the power system. In this paper, a new realistic model considering practical applications and limitations is proposed. This practical model is achieved by considering different generating units for each area and GRC, GDB and time delay of both communication channels simultaneously. A novel CHEPSO based PID control methodology is proposed first time for a realistic two area multiunit hydro thermal interconnected power system. To improve both steady-state and transient performances, logical and novel objective function is formulated. In this paper, multi-objectives like area control error $(A C E), M_{p}, S S E$ are converted into single objective with tuned weight coefficient. The proposed algorithm is compared with RCGA, GPSO, EPSO algorithms. The performance comparison demonstrates that CHEPSO with developed objective function is established to be the best in order to optimize the parameter because of its convergence superiority.

\section{REALISTIC LFC SYSTEM}

\section{A. Multi-area Interconnected Power System}

The different control areas of the interconnected power system are connected via tie line which is the basis for the load sharing between them. Due to load disturbance within a control area, the frequency and load sharing of all the areas experience a transient change. The stability of the whole system and balance between connected areas will be lost. To regain the normal steady state operation and to minimize the frequency and tie power deviation, the LFC control mechanism becomes active and generate appropriate signal for the participating generating units according to their participation factors. In general, LFC is accomplished by suitable controller connected in each area. The input to the controller is the area control error $(A C E)$. The $A C E$ of each control area is the linear combination of frequency and tie-line power deviation $\left(\Delta p_{t i e}\right)[1]$.

$$
A C E_{k}=B_{k} \Delta f_{k}+\Delta P_{\text {tie }}
$$

Where $k=(1,2)$, represent the area number, $B=$ Frequency bias factor and $\Delta f=$ Frequency deviation.

In power system operation, each control area is responsible for its own load change and tries to reduce its own $A C E$ to zero. The balance between connected areas and zero steady state deviation of frequency and tie power is achieved by making $A C E$ to zero through LFC.

\section{B. Realistic LFC with Physical Limitations}

In this work, a more practical approach is considered during selection of power generating units. In each area, three distinct power generating units such as reheat, non-reheat and hydro units are considered for the design purpose. The parameters' values of all generating units are taken different to get practical analysis of the LFC system. The basic physical constraints (GRC, GDB and Time Delay) and related dynamics have been considered to get a realistic model and accurate understanding of the LFC studies. The rate at which the generating unit output is changed is termed as GRC. The GRC of reheat, non-reheat and hydro unit is in the order of $3 \%$ /minute, $5-10 \% /$ minute and $100 \%$ maximum continuous rating $(\mathrm{MCR}) /$ minute respectively. The speed governor dead band is defined as the total magnitude of the steady state speed change within which there will be no change in the position of the governor controlled valves. Dead band generally expressed in percent of the rated speed/frequency. The GDB of steam turbine and hydro turbine governor are $0.06 \%$ and $0.02 \%$ of rated speed respectively. The nominal rated frequency $(f)$ is $60 \mathrm{~Hz}$. The time delay introduced by the communication channels plays a crucial role for the stable operation of the power system. Increasing the decentralization and restructuring, control of the power system highly needs the support of open communication infrastructure for data gathering which introduces a time delay [5],[6]. This delay, if does not cater in proper way, would degrade the dynamic performance of the LFC and in the extreme case, it will destabilize the whole system. In the present study, a time delay of 2 seconds is considered. The transfer function model of the two area power system 
considering all the physical constraints is depicted in Fig. 1 and the system parameters are given in appendix A. Following a load disturbance, the participating generating units generate power according to their participation factors to match the load demand. Depending on usefulness, the participation factors of reheat, non-reheat and hydro generating units are taken as $0.5,0.3$ and 0.2 respectively for both the areas.

\section{OBJECTIVE FUNCTION}

The intelligent control design for PID load-frequency controller is presented in this paper. The objective of the proposed design is to control the frequency and tie-line power in such a way, so as to achieve the same performance in changing environment and parameter uncertainties. The input to the PID controller is the $A C E$ and control input to power system is the actuated output signal of PID controller. The control inputs of the power system $\left(y_{1}\right.$ and $\left.y_{2}\right)$ are obtained as

$$
\begin{aligned}
& y_{1}=K_{p 1} \times A C E_{1}+K_{i 1} \times \int A C E_{1} d t+K_{d 1} \times d\left(A C E_{1}\right) / d t \\
& y_{2}=K_{p 2} \times A C E_{2}+K_{i 2} \times \int A C E_{2} d t+K_{d 2} \times d\left(A C E_{2}\right) / d t
\end{aligned}
$$

In LFC scheme, true optimal solutions are achieved by applying a particular control strategy. True optimal solutions means zero steady state error, minimum overshoot, minimum settling time, minimum over all oscillation and good damping characteristic of the output frequencies and tie-line power. In order to obtain fast convergence and true optimal solutions, logical objective functions are formulated. The objective functions are derived by considering steady state and transient response specifications and proper selection of weighting factors. First time, in addition to $A C E, S S E$ and $M_{p}$ are considered as objective functions to improve both steady state and transient performances. Suitable choice of response specifications for formation of objective functions is highly necessary to obtain better steady state and transient performances. The wrong selection of weighting factors may also lead to incompatible numerical value of each term of objective functions which gives incorrect result. In this work, a significant effort is given to design the best objective function. For this purpose, a set of objective function is developed for finding out the best combination of response specifications and weighting factors. The developed objective functions are:

$$
\text { I. } J_{k}=\int\left(A C E_{k}\right)^{2} d t=E_{k}
$$

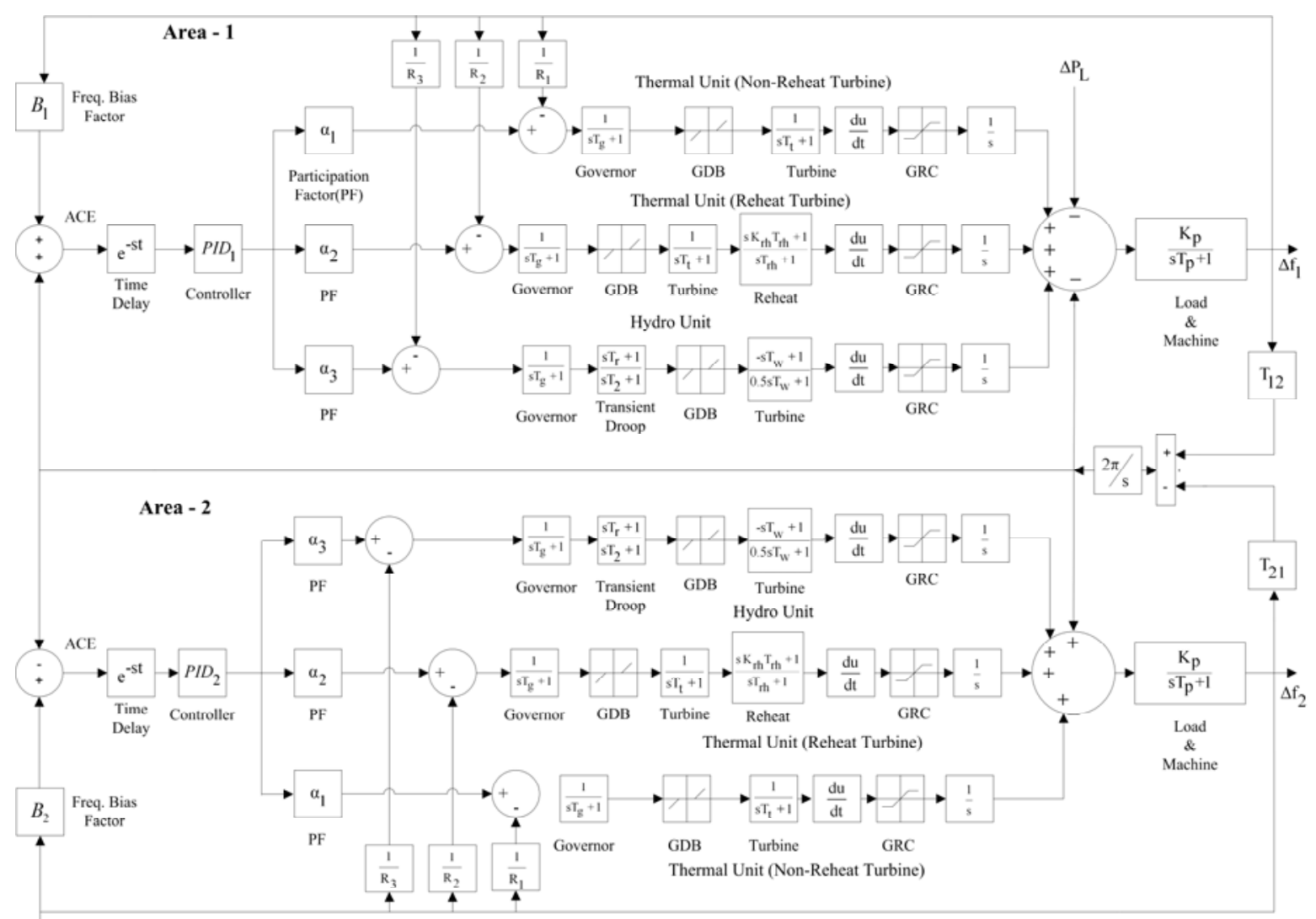

Fig. 1. Transfer function model of two area interconnected realistic power system 


$$
\begin{aligned}
& \text { II. } J_{k}=E_{k}+S S E_{k} \\
& \text { III. } J_{k}=E_{k}+0.1 \times M_{p k} \\
& \text { IV. } J_{k}=E_{k}+0.1 \times M_{p k}+S S E_{k}
\end{aligned}
$$

Where $k=(1,2)$, represent the area number, $E=$ Square integral of $A C E, M_{p}=$ Maximum overshoot, $S S E=$ Steady state error of the output frequency.

Weighting coefficients are used to provide equal weightage / priority for all terms of the objective function $(J)$. Our main target is to reduce SSE to zero. The tolerance is set to $10^{-4}$ i.e. if SSE is less than $10^{-4}$, the main criteria for the convergence is achieved. The other terms of the objective function should be equivalence of the main term (SSE). Considering this philosophy, the weighting coefficient of each term of ' $J$ ' is evaluated.

\section{IV.Proposed ALgorithm}

The complex intractable and nonlinear control problems can efficiently handle by the soft computing techniques compared to conventional classical and modern control approaches. These are robust, not model specific and are useful when the system is operating over an uncertain operating range. This paper presents the LFC analysis on a specific realistic control configuration by evolutionary computation based algorithm.

\section{A. General Particle Swarm Optimization (GPSO) Algorithm}

The global solution using PSO is achieved by competition/contest and cooperation/collaboration among the individuals of a population set. The algorithm begins with a set of randomly generated particles with specified range and sizes. Each particle is associated with a velocity and a position. The updated value of each individual will be achieved through previous information and best position of the particles and its companions. The velocity and new position of $i^{\text {th }}$ particle in $n$-dimensional space will be assigned using the following equations [14].

$$
\begin{aligned}
v_{i}^{t} & =w_{i} \times v_{i}^{t}+c_{1} \times u_{1} \times\left(p b_{i}^{t}-x_{i}^{t}\right)+c_{2} \times u_{2} \times\left(g b_{i}-x_{i}^{t}\right) \\
x_{i}^{t} & =x_{i}^{t}+v_{i}^{t}
\end{aligned}
$$

Where $v_{i}^{t}, x_{i}^{t}, p b_{i}^{t}$ are the velocity, position and current best position of the $i^{t h}$ particle at $t^{\text {th }}$ iteration. $g b_{i}$ denotes the global best position of the whole particle up to the present iteration. $u_{1}, u_{2}$ are the random number in the range [0,1], $c_{1}, c_{2}$ are the positive constant called constriction factors.$w_{i}$ is the inertia weight for the velocity of $i^{\text {th }}$ particle and is obtained by $w=w_{\text {min }}+$ rand ()$/ 2$. In GPSO, $c_{1}=c_{2}:\left(c_{1}, c_{2}\right) \in[0,4]$ and $w$ lies within the range $[0,1]$. The solution $g b_{i}$ and the corresponding particles are obtained after fulfilling the stopping condition.

\section{B. Exponential PSO (EPSO) Algorithm}

The convergence of the general PSO (GPSO) is greatly depends on constriction factors $\left(c_{1} \& c_{2}\right)$ and inertia weight $(w)$. These variables must be selected properly according to the problem to get the better convergence. In this problem $c_{1}=c_{2}=1.44445$ are proposed. Inertia weight is the factor which controls the impact of the previous velocity on its present one. At the beginning of the iteration, high value of inertia weight will facilitate the global exploitation and low value of $w$ at the end of iteration will help to achieve the local exploration efficiently. So to achieve true optimal solution inertia weight must be adaptive in nature.

1) Adaptive Inertia Weight (AIW): To obtain suitable value of $\mathrm{w}$ for making balance between global exploitation and local exploration, $w$ is made exponentially vary [18] with the iteration and is determined as eqn. (10).

$$
w(t)=\left(w_{\max }-w_{\min }-m_{1}\right) \exp \left(\frac{1}{1+m_{2}\left(\frac{t}{T}\right)}\right)
$$

Where $w_{\max }, w_{\min }$ are the maximum and minimum value of $w ; m_{1}, m_{2}$ are the control factors; $t=$ current iteration and $T=$ maximum no. of iteration. The above function is a nonlinear function and varies exponentially with the iteration. This adaptive function facilitate high ' $w$ ' at starting and low ' $w$ ' at the end to stop premature convergence and enhance local search respectively. The value of $m_{1}$ and $m_{2}$ must be selected carefully to attain proper balance between global exploitation and local exploration. This new adaptive $w$ is dependent on present iteration, maximum iteration and is developed in such a way that it maintains the convergence capability. 


\section{Chaotic Exponential PSO (CHEPSO) Algorithm}

The EPSO algorithm does not provide satisfactory performance for the nonlinear LFC model. This algorithm is also unable to provide suitable multiple solutions. To overcome these drawbacks and to avoid local optimal solution, chaotic dynamics is introduced to EPSO algorithm. Chaos is the characteristic of non linear system with deterministic dynamic behavior that has ergodic and stochastic properties, random and unpredictable. Chaos has been widely used in many optimization problems because of its dominant searching capability and easy implementation. It is very sensitive to initial conditions, parameter used and parameter variation. In chaotic optimization problem, chaos variables are generated by using chaotic logistic map and incorporated as disturbance variables to the decision variables. The population diversity greatly improved due to the ergodicity property of the chaos variables and the algorithm starts to search for the global solution. This minimizes the chances of premature convergence and sticking into local minima. In this study, a completely new chaotic exponential PSO (CHEPSO) technique is developed by combining EPSO and chaotic local search.

1) Chaotic Logistic Map: In this study of chaotic optimization, chaotic variables (cv) are generated by using the following logistic equation which is very sensitive to initial conditions [20].

$$
(c v)_{i}^{t+1}=\mu(c v)_{i}^{t}\left[1-(c v)_{i}^{t}\right],(c v)_{i}^{t} \in(0,1)
$$

Where $i=1,2,3 \ldots \mathrm{n}, t=$ iteration number, $\mu$ is the control parameter which stabilizes the $c v$ 's and belongs to [0, 4], $c v=\mathrm{n}$-dimensional vector $=\left(c v_{1}, c v_{2}, c v_{3} \ldots \ldots . . . c v_{n}\right)$ and $c v_{i}^{t}$ lies in the range $(0,1)$. The chaotic behavior represented by equation (11) changes due to variation of $\mu$. The complete chaotic dynamic is obtained for $\mu=4$ and initial value $c v_{i}^{0}$ belongs to $(0,1)$ but $c v_{i}^{0}$ does not belongs to $(0,0.25,0.5,0.75,1)$. In this paper, $\mu$ is taken as 4 .

2) Chaotic Local Search: For avoiding local minimum solution, chaotic local search (CLS) is incorporated in the proposed algorithm during the optimization process. The local exploitation of the search space is carried out using CLS to obtain the global solution. CLS is based on chaotic maps of chaos theory represented by the logistic equation (11).

The step by step procedures of CLS for the minimization problem are demonstrated as follows:

[Step 1]: Obtain the minimum objective function value $\left(o b j^{\text {best }}\right)$ and the corresponding $i^{\text {th }}$ particle $\left(x_{\min , i}^{t}\right)$ among the whole particles at $t^{\text {th }}$ iteration.

[Step 2]: Obtain the maximum objective function value $\left(o b j^{\text {worst }}\right)$ and the corresponding $i^{\text {th }}$ particle $\left({ }^{x_{\max , i}^{t}}\right)$ among the whole particle at $t^{\text {th }}$ iteration.

[Step 3]: Determine the chaotic variable $c v_{i}^{t} \in(0,1)$ for $t^{\text {th }}$ iteration using following equation

$$
c v_{i}^{t}=\frac{\left|x_{i}^{t}-x_{\min , i}^{t}\right|}{\left|x_{\max , i}^{t}-x_{\text {min }, i}^{t}\right|}
$$

[Step 4]: Determine the chaotic variable $c v_{i}^{t+1}$ for the next iteration using the logistic equation (11).

[Step 5]: Determine the decision variables for the next iteration using chaotic variables from the equation:

$$
x_{i}^{t+1}=x_{i}^{t}+c v_{i}^{t+1}
$$

[Step 6]: Evaluate the new solution with the obtained decision variables $x_{i}^{t+1}$.

\section{Proposed CHEPSO Algorithm for LFC}

LFC is an important control process that runs continuously to balance the generation and load in power system to achieve best steady state and transient performances. PID controller, being the most efficient controller in industrial applications, is used to obtain the good LFC mechanism. The main objectives of this proposed work are to zero SSE, low settling time, minimum overshoot and less oscillation of tie power deviation and frequency deviations of both the areas. Since the control areas are not same, two different PID controllers are required to achieve the desired result. The desired result is achieved by getting true optimal solutions of PID gains such as $K_{p}, K_{i}$ and $K_{d}$ for both the controllers. These gains are treated as decision variables (particles) which will control the frequency and tie-line power deviation, steady state and transient performances of the power system. In this work, CHEPSO technique is uniquely used to tune the control parameters of the LFC problem. Exhaustive literature survey is carried out in this field and it is observed that CHEPSO technique never been used earlier to solve the load frequency control problem. Since the proposed power system model is a practical model, at the beginning of the iteration, the particles $\left(K_{p}, K_{i}\right.$ and $\left.K_{d}\right)$ are initialized within a specified practical range. Range selection of controller gains is an important issue as wrong selection of range will prolong the convergence time and aggravate the performance of the optimization process. In this work, range of 


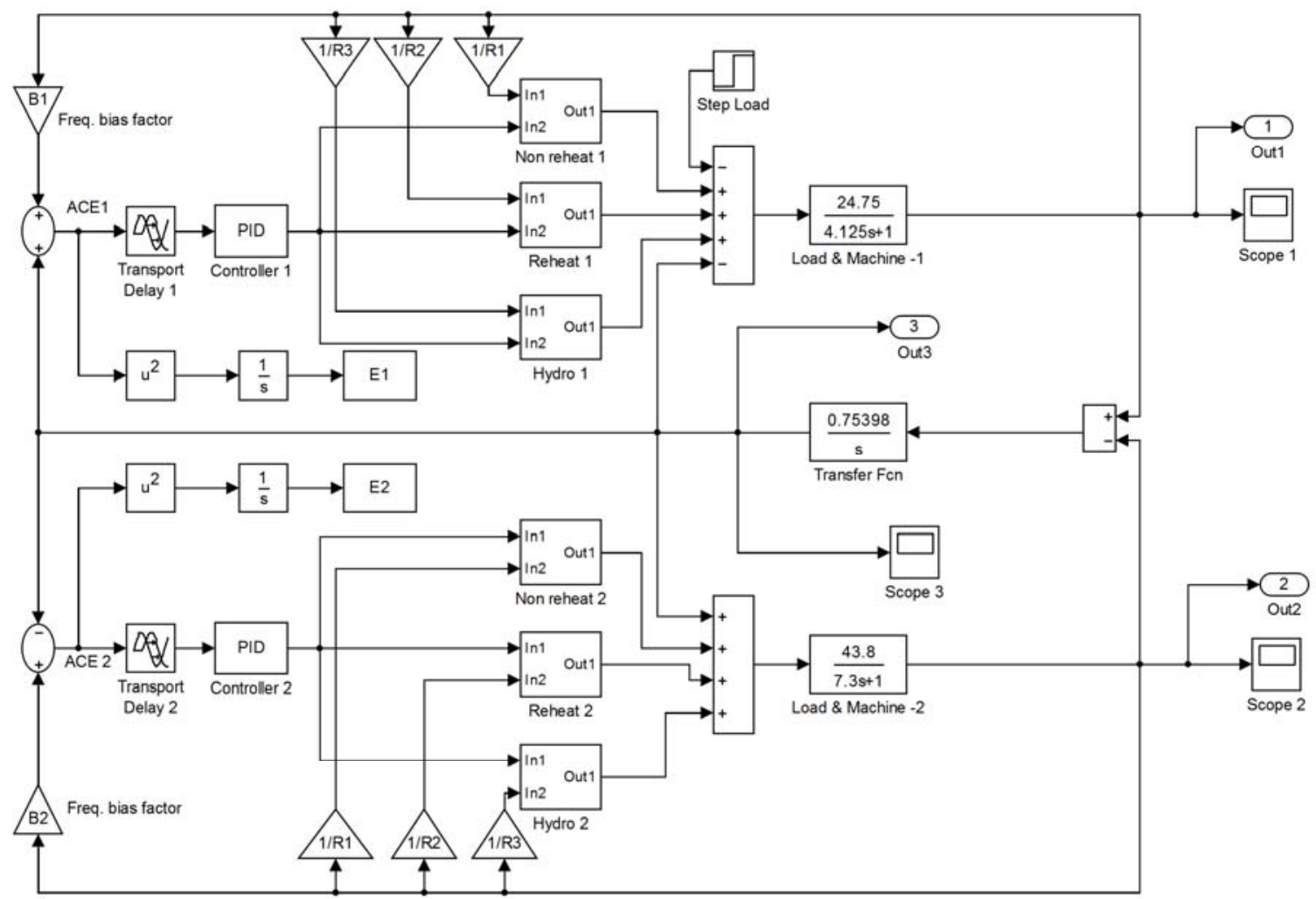

Fig. 2. Simulink model of the realistic LFC system

$K_{p}, K_{i}$ and $K_{d}$ are taken as -2 to 2 . The simulation process of the present study becomes complicated due to complex structure, different parameter values and nonlinearities like GRC, GDB and time delay present in the system. The simulation is carried out by developing two Matlab program and one Simulink model. The Simulink model is shown in Fig. 2. The graphical representation of the execution procedure is given in Fig. 3. The simulations are realized by step load change of $0.1\left(\Delta \mathrm{P}_{\mathrm{L}}=0.1\right)$ at area 1 .

The decision variables $\left(K_{p}, K_{i}, K_{d}\right)$ are initialized in the main CHEPSO program and fed to the Simulink model. From the Simulink model the outputs with respect to time for tie power deviation and frequency deviations of both the areas are obtained. With these outputs, the objective function values are calculated in script program file. In the main CHEPSO program, pbest and gbest solutions are obtained using the calculated objective function values. If the fitness value of pbest solution is less than the fitness value of gbest solution, then pbest fitness value and the corresponding pbest solution will be the gbest fitness value and gbest solution respectively. Otherwise, gbest value and gbest solution will remain same. The particles are updated in the CHEPSO program using different rules of CHEPSO algorithm. This process runs continuously until stopping

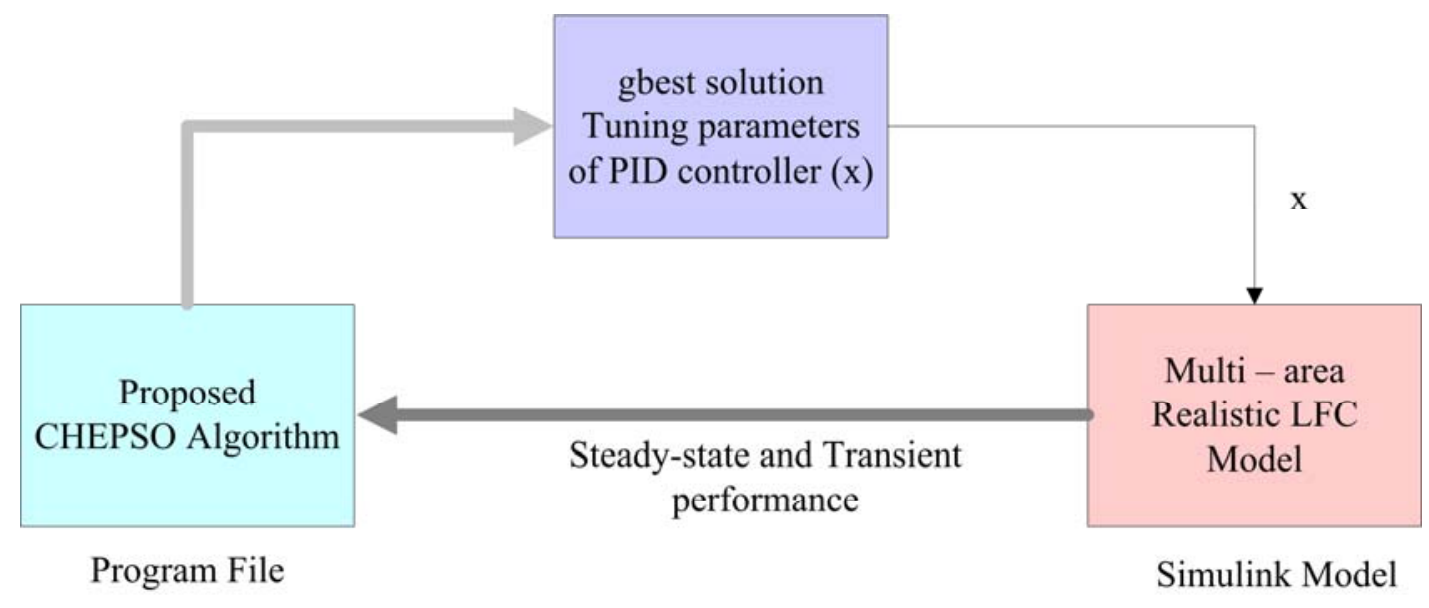

Fig. 3. Graphical representation of the execution procedure 


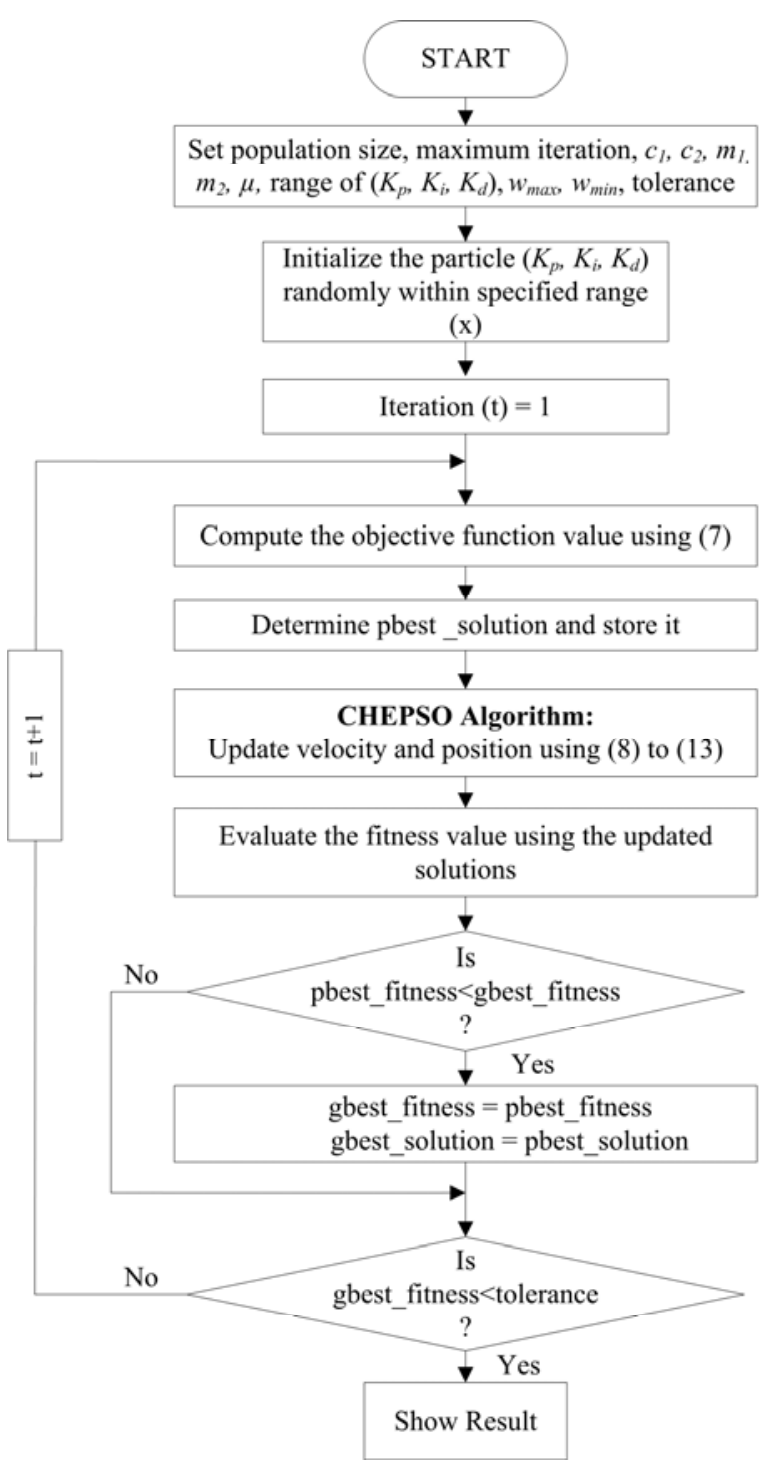

Fig. 4. Flowchart of CHEPSO for LFC

condition is satisfied. The step by step application of the developed algorithm for this optimization problem is enumerated in Fig. 4.

\section{VI.RESULTS AND ANALYSIS}

\section{A. Determination of Best Objective Function}

Total four objective functions are developed and their performances are carried out using proposed CHEPSO algorithm and MATLAB simulation. Among the four objective functions, the best objective function is determined considering both transient and steady state performances. The optimal tuning parameters of the PID controllers are given in Table I. Table II shows the transient and steady state specifications for all objective functions. The frequency and tie power deviation $\left(\Delta f_{l}, \Delta f_{2} \& \Delta P_{t i e}\right)$ characteristics for all the objective functions are shown in Fig. 5 to Fig. 8. As the parameters of governor, turbine and load/machine are not same for area 1 (a1) and area 2 (a2), the tuning parameters of PID controllers for a1 and a2 will not be equal.

If single objective function like ACE is used, it does not provide stable output. For objective function I, the response specifications $M_{p}, t_{s}$ and $S S E$ are very high. A noticeable improvement of $S S E$ and $t_{s}$ is observed when $S S E$ is incorporated as objective function along with the $A C E$ (Eq. 5). Similarly, when $M_{p}$ with proper weighting 
TABLE I. PID Control Gains of Each Objective Function

\begin{tabular}{|c|c|c|c|c|c|c|}
\hline & \multicolumn{3}{|c|}{ Area 1 } & \multicolumn{3}{c|}{ Area 2 } \\
\hline Obj. Func. & $\boldsymbol{K}_{\boldsymbol{p} \mathbf{1}}$ & $\boldsymbol{K}_{\boldsymbol{i} \mathbf{1}}$ & $\boldsymbol{K}_{\boldsymbol{d} \mathbf{1}}$ & $\boldsymbol{K}_{\boldsymbol{p} 2}$ & $\boldsymbol{K}_{\boldsymbol{i} 2}$ & $\boldsymbol{K}_{\boldsymbol{d} \mathbf{2}}$ \\
\hline I & -4.2072 & -1.7746 & 0.7363 & 1.1861 & -0.4842 & 0.1564 \\
\hline II & 0.7676 & -0.5032 & 0.1027 & 0.9694 & -0.35156 & 0.4461 \\
\hline III & 1.3433 & -0.2145 & 0.0889 & 1.4103 & -0.3621 & 0.1033 \\
\hline IV & 0.8330 & -0.1454 & 0.1681 & 1.2941 & -0.1981 & 0.2774 \\
\hline
\end{tabular}

TABLE II. Steady State and Transient Specifications of the Response of LFC

\begin{tabular}{|c|c|c|c|c|c|c|c|c|c|}
\hline $\begin{array}{c}\text { Obj. } \\
\text { Func. }\end{array}$ & \multicolumn{3}{|c|}{$\begin{array}{c}\text { Max. Overshoot } \\
\left(\boldsymbol{M}_{\boldsymbol{p}}\right)^{*} \mathbf{1 0}^{-4}\end{array}$} & \multicolumn{3}{c|}{$\begin{array}{c}\text { Settling Time } \\
{\left[\boldsymbol{t}_{\boldsymbol{s}}(\mathbf{s e c})\right.}\end{array}$} & \multicolumn{3}{c|}{$\begin{array}{c}\text { Steady State Error } \\
(\mathbf{S S E})^{*} \mathbf{1 0}^{-5}\end{array}$} \\
\hline & Area 1 & Area 2 & $\begin{array}{c}\text { Tie- } \\
\text { Line }\end{array}$ & Area 1 & Area 2 & Tie-Line & Area 1 & Area 2 & Tie-Line \\
\hline I & 287 & 341 & 46 & 49.79 & 49.89 & 49.98 & 800 & 860 & 140 \\
\hline II & 150 & 91 & 22 & 28.03 & 27.53 & 29.22 & 2.717 & 2.071 & 2.598 \\
\hline III & 32 & 36 & 19 & 26.15 & 26.6 & 28.21 & 5.163 & 4.981 & 2.976 \\
\hline IV & 4.23 & 4.72 & 9.88 & 20.17 & 20.37 & 20.68 & 1.743 & 1.762 & 1.648 \\
\hline
\end{tabular}
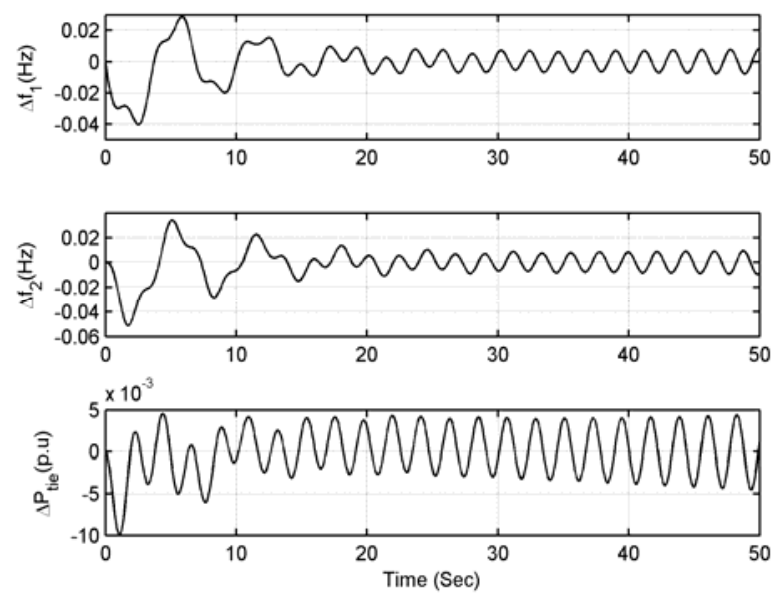

Fig. 5. Transient response of LFC using objective function I
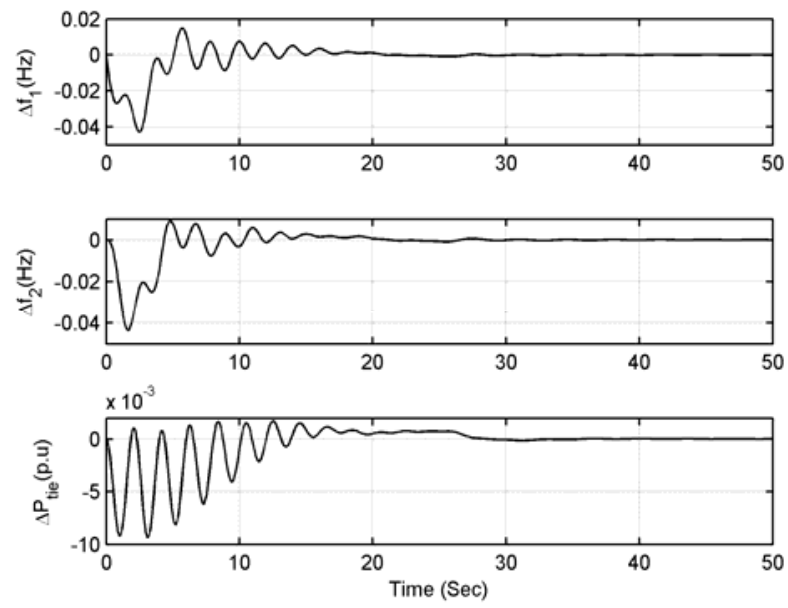

Fig. 6. Transient response of LFC using objective function II 

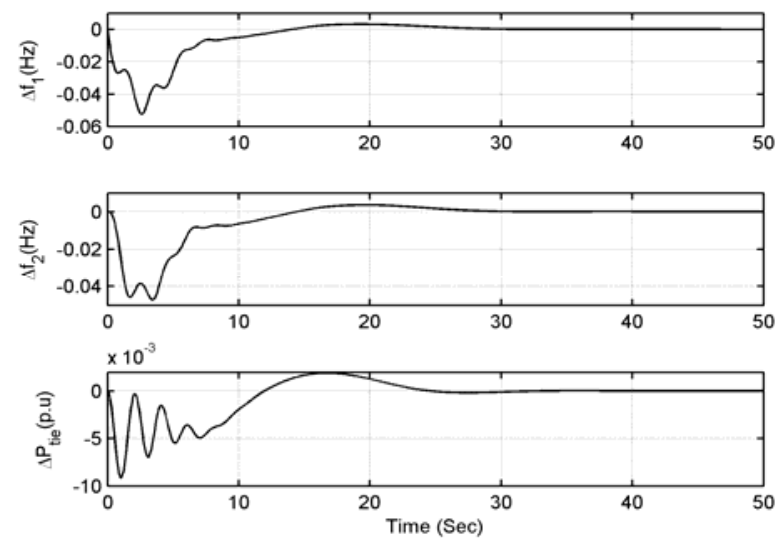

Fig. 7. Transient response of LFC using objective function III
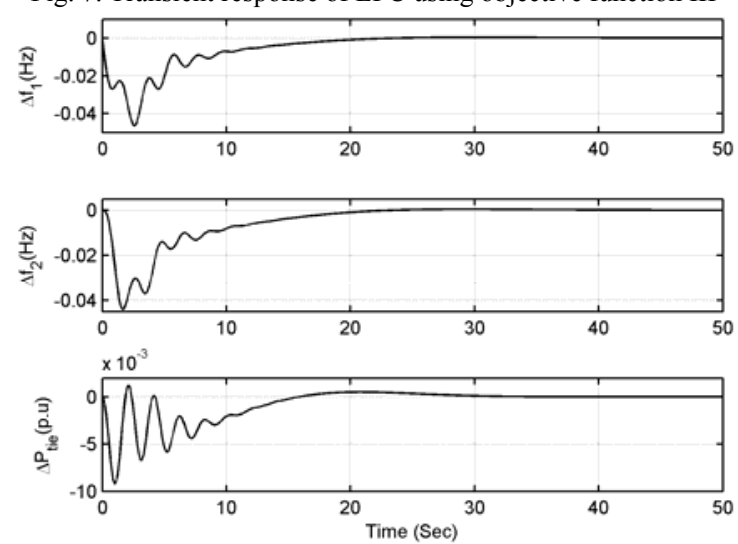

Fig. 8. Transient response of LFC using objective function IV

factor is added to $A C E$ (Eq. 6), both $M_{p}$ and $t_{s}$ are significantly improved compare to objective function I. From Fig. 8 and Table II, it is concluded that the best results like lowest $M_{p}$, $t_{s}$ and $S S E$ are achieved using function IV. So, the objective function IV can be efficiently applied to the nonlinear LFC model.

\section{B. Tuning of PID Controller and Analysis}

The optimal tuning parameters of the PID controllers are obtained by running the simulation 50 times for each algorithm. Table III shows the best tuned control parameter of the control system. The steady state and transient response specifications are depicted in Table IV. The transient responses of frequency deviation for area 1, area 2 and tie power deviation using different techniques are given in Fig. 9 to Fig. 11.

TABLE III. Tuned Control Parameters

\begin{tabular}{|c|c|c|c|c|c|c|}
\hline & \multicolumn{3}{|c|}{ Area 1 } & \multicolumn{3}{c|}{ Area 2 } \\
\hline Method & $\boldsymbol{K}_{\boldsymbol{p} \mathbf{1}}$ & $\boldsymbol{K}_{\boldsymbol{i 1}}$ & $\boldsymbol{K}_{\boldsymbol{d} \mathbf{1}}$ & $\boldsymbol{K}_{\boldsymbol{p} \mathbf{2}}$ & $\boldsymbol{K}_{\boldsymbol{i} 2}$ & $\boldsymbol{K}_{\boldsymbol{d} \mathbf{2}}$ \\
\hline RCGA & 1.3400 & -0.1247 & 0.1867 & 1.3800 & -0.3547 & 0.0474 \\
\hline GPSO & 1.3725 & -0.1141 & 0.2711 & 1.4319 & -0.2813 & 0.1823 \\
\hline EPSO & 1.2275 & -0.1497 & 0.2017 & 1.4219 & -0.3201 & 0.0791 \\
\hline CHEPSO & 0.8330 & -0.1454 & 0.1681 & 1.2941 & -0.1981 & 0.2774 \\
\hline
\end{tabular}

TABLE IV. Transient and Steady State Specifications

\begin{tabular}{|c|c|c|c|c|c|c|c|c|c|}
\hline \multirow[t]{2}{*}{ Algorithm } & \multicolumn{3}{|c|}{ Max. Overshoot $\left(M_{p}\right) * 10^{-4}$} & \multicolumn{3}{|c|}{ Settling Time $\left[t_{s}(\mathrm{sec})\right]$} & \multicolumn{3}{|c|}{$\begin{array}{l}\text { Steady State Error(SSE)* } \\
\qquad 10^{-5}\end{array}$} \\
\hline & Area 1 & 2 & $\begin{array}{l}\text { Tie- } \\
\text { Line }\end{array}$ & $\begin{array}{c}\text { Area } \\
1\end{array}$ & Ar & $\begin{array}{l}\text { Tie- } \\
\text { Line }\end{array}$ & Area 1 & Area 2 & $\begin{array}{l}\text { Tie- } \\
\text { Line }\end{array}$ \\
\hline RCGA & 2 & 29 & 15 & 32.73 & & 32.04 & 07 & & 3.5678 \\
\hline GPSO & 26 & 29 & 1 & .5 & & 9 & 4852 & 2915 & .9584 \\
\hline EPSO & 22 & 25 & 14 & 29.84 & 30 & 28.19 & 1.9 & 1.9273 & 1.9356 \\
\hline CHEPSO & 4.23 & 4.72 & 9.88 & 20.17 & 20.37 & 27.68 & 1.7431 & 1.7624 & 1.6479 \\
\hline
\end{tabular}


ISSN (Print) : :2319-8613

ISSN (Online) : 0975-4024

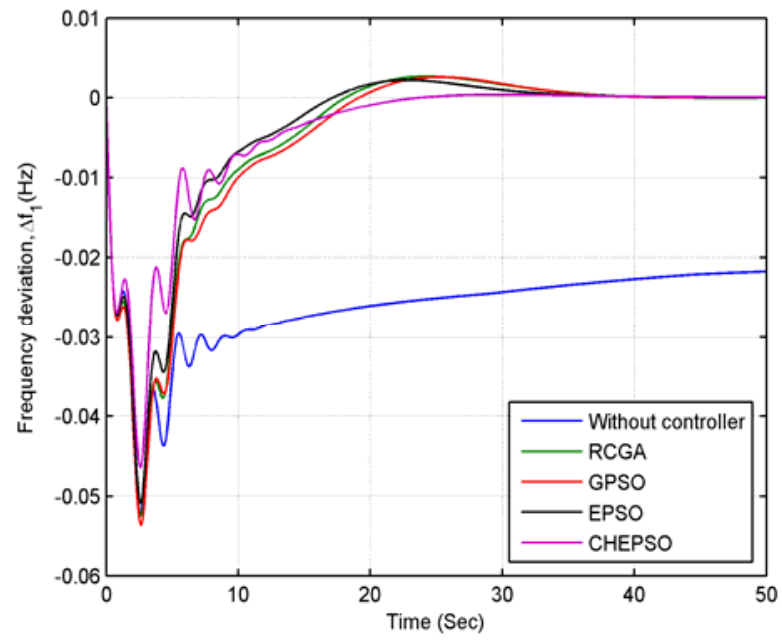

Fig. 9. Frequency deviation of area 1

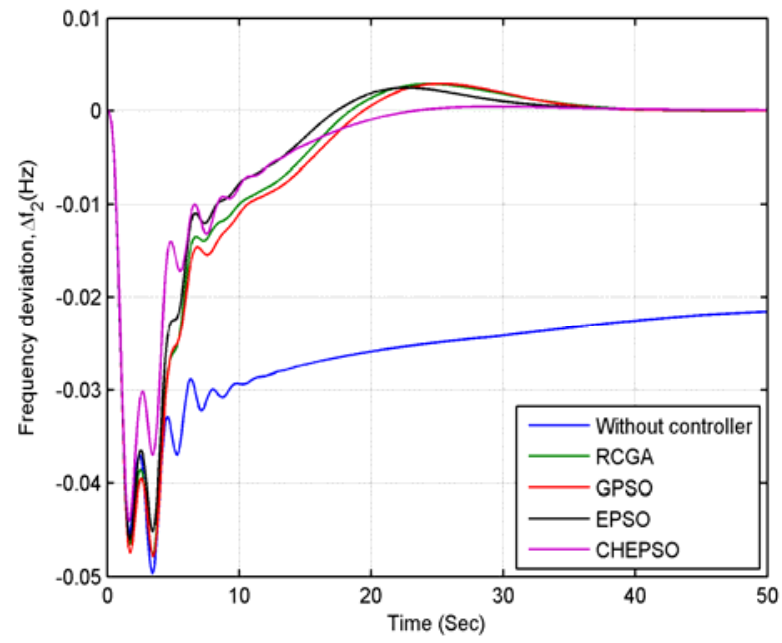

Fig. 10. Frequency deviation of area 2

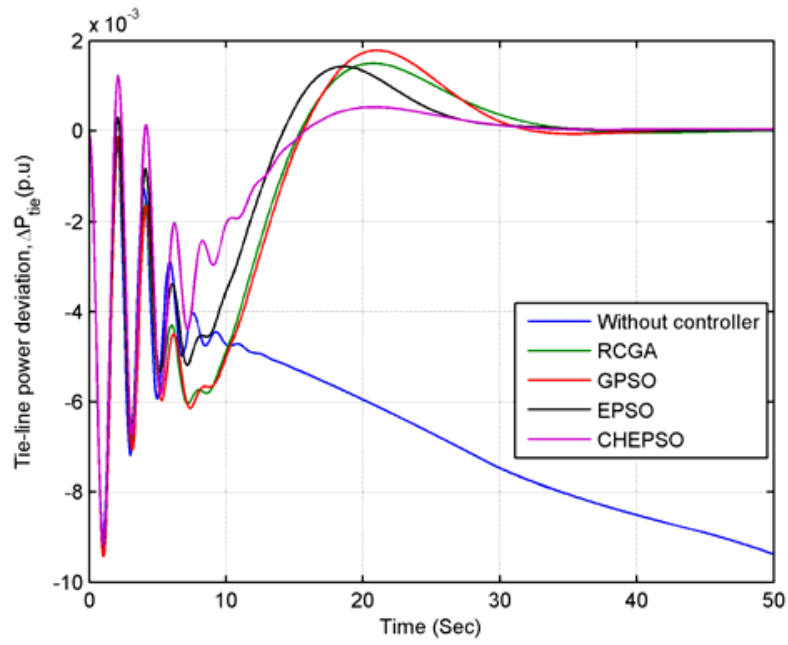

Fig. 11. Tie- line power deviation 
From Table IV and Fig. 9 to Fig. 11, it is observed that the transient specifications for RCGA and GPSO techniques are almost same. EPSO technique provides comparatively better performances than that of RCGA and GPSO techniques. The CHEPSO based control strategy produces best solution compare to RCGA, GPSO and EPSO techniques. The result shows that the PID tuned by CHEPSO with the developed objective function improves the control of the power system by minimizing the frequency and tie power deviation to almost zero and improving the damping characteristic. Therefore the system stability is also improved.

\section{Useful Multiple Solutions}

The CHEPSO technique can efficiently produce many useful solutions for the composite LFC model. As a sample, some suitable multiple solutions of the PID controller are given in Table V. It is observed from the Table $\mathrm{V}$ that multiple solutions of the tuning parameters are obtained for the same improved performances. The tuning parameters $K_{p}, K_{i}$ and $K_{d}$ for both the areas are also different. For planning and design of realistic LFC model, these types of multiple solutions are very helpful as there are limitations in PID controller (Hardware devices) and ranges of control gains. Hence, the proposed algorithm is very effective and useful for the designer and planning engineers for the modeling of LFC.

\section{VII.CONCLUSION}

In this work, LFC problem of two area interconnected nonlinear realistic power system with thermal and hydro generating units is considered. For the practical power system, six (three for each area) widely used generating units such as reheat, non-reheat and hydro units with different real time system parameters are considered. To get an accurate LFC design, practical security constraints such as GRC, GDB and time delay are also considered. A new and unique objective function is developed by considering important transient and steady state response specifications with appropriate selection of weight factors. A CHEPSO based PID control methodology is proposed first time to obtain the optimum gains of the PID controllers and true optimal solutions

TABLE V. Useful Multiple Solutions using CHEPSO Algorithm

\begin{tabular}{|c|c|c|c|c|c|c|c|c|c|c|c|}
\hline \multicolumn{3}{|c|}{ Control Parameters } & \multicolumn{3}{|c|}{$\begin{array}{l}\text { Max. Overshoot } \\
\left(M_{p}\right)^{*} 10^{-4}\end{array}$} & \multicolumn{3}{|c|}{$\begin{array}{l}\text { Settling Time } \\
{\left[t_{s}(\mathrm{sec})\right]}\end{array}$} & \multicolumn{3}{|c|}{$\begin{array}{l}\text { Steady State Error } \\
(S S E)^{*} 10^{-5}\end{array}$} \\
\hline $\begin{array}{l}K_{p 1} \\
K_{p 2}\end{array}$ & $\begin{array}{l}K_{i 1} \\
K_{i 2}\end{array}$ & $\begin{array}{l}K_{d 1} \\
K_{d 2}\end{array}$ & $\begin{array}{l}\text { Are } \\
\text { a1 }\end{array}$ & $\begin{array}{l}\text { Area } \\
2\end{array}$ & $\begin{array}{l}\text { Tie- } \\
\text { line }\end{array}$ & $\begin{array}{l}\text { Area } \\
1\end{array}$ & $\begin{array}{l}\text { Area } \\
2\end{array}$ & $\begin{array}{l}\text { Tie- } \\
\text { line }\end{array}$ & $\begin{array}{l}\text { Area } \\
1\end{array}$ & $\begin{array}{l}\text { Area } \\
2\end{array}$ & $\begin{array}{l}\text { Tie- } \\
\text { line }\end{array}$ \\
\hline $\begin{array}{l}1.2275 \\
1.4219\end{array}$ & $\begin{array}{l}-0.1497 \\
-0.3201\end{array}$ & $\begin{array}{l}0.2017 \\
0.0791\end{array}$ & 22 & 25 & 14 & 29.49 & 30.20 & 27.8 & 8.035 & 7.910 & 2.244 \\
\hline $\begin{array}{l}1.0496 \\
1.3908\end{array}$ & $\begin{array}{l}-0.1384 \\
-0.3930\end{array}$ & $\begin{array}{l}0.0920 \\
-0.0234\end{array}$ & 14 & 14 & 6.13 & 30.3 & 32.1 & 34.11 & 10.388 & 10.501 & $\begin{array}{c}2.794 \\
7\end{array}$ \\
\hline $\begin{array}{l}0.9504 \\
1.1287\end{array}$ & $\begin{array}{l}-0.1464 \\
-0.2546\end{array}$ & $\begin{array}{l}0.0417 \\
0.1938\end{array}$ & 8.92 & 9.93 & 7.88 & 22.17 & 22.62 & 30.11 & 10.47 & 10.426 & $\begin{array}{c}2.924 \\
9\end{array}$ \\
\hline $\begin{array}{l}0.8942 \\
1.0416\end{array}$ & $\begin{array}{l}-0.0947 \\
-0.4892\end{array}$ & $\begin{array}{l}0.1640 \\
0.2560\end{array}$ & 6.69 & 7.3 & 10 & 21.32 & 21.64 & 28.86 & 10.658 & 10.775 & $\begin{array}{c}2.833 \\
1\end{array}$ \\
\hline $\begin{array}{l}0.8897 \\
0.6793\end{array}$ & $\begin{array}{l}-0.1711 \\
0.2249\end{array}$ & $\begin{array}{l}0.2482 \\
0.3027\end{array}$ & 5.27 & 6.41 & 11 & 21.42 & 23.18 & 30.74 & 8.3616 & 7.7291 & $\begin{array}{c}3.677 \\
3\end{array}$ \\
\hline
\end{tabular}

for the LFC problem. A comparative study has been carried out among developed CHEPSO, RCGA, GPSO and EPSO based tuning techniques. The comparison result shows that compared to RCGA,GPSO and EPSO techniques, CHEPSO based controller design can provide better performance by generating true optimal gains, optimal transient performances and can give good damping performance of frequency and tie power deviation. This proposed technique can be applied easily to other complex large scale multi-area nonlinear interconnected power system because of its superior convergence ability. 


\section{APPENDIX}

\section{A. System Parameters}

The typical values of the system parameters are given in Table VI.

\section{B. Algorithm Parameters}

Crossover Probability $=0.8$; Mutation Rate $=0.02$; Constriction Factors $\left(c_{1}=c_{2}\right)=1.44445 ; w_{\max }=0.95$; $w_{\min }=0.4 ; m_{1}=0.2 ; m_{2}=7$.

TABLE VI. The Typical Values of the System Parameters

\begin{tabular}{|c|c|c|c|c|c|c|c|c|}
\hline & \multicolumn{4}{|c|}{ Area 1} & \multicolumn{4}{|c|}{ Area 2} \\
\hline & $\begin{array}{c}\text { Non } \\
\text { Reheat }\end{array}$ & Reheat & Hydro & $\begin{array}{l}\text { Load \& } \\
\text { Machine }\end{array}$ & $\begin{array}{l}\text { Non } \\
\text { Reheat }\end{array}$ & Reheat & Hydro & $\begin{array}{l}\text { Load \& } \\
\text { Machine }\end{array}$ \\
\hline $\begin{array}{l}\text { Governor Time } \\
\text { Constant } \mathrm{T}_{\mathrm{g}}(\mathrm{s})\end{array}$ & 0.07 & 0.06 & 0.4 & - & 0.08 & 0.08 & 0.2 & - \\
\hline $\begin{array}{l}\text { Turbine Time Constant } \\
\mathrm{T}_{\mathrm{t}}(\mathrm{s})\end{array}$ & 0.4 & 0.36 & - & - & 0.3 & 0.42 & - & - \\
\hline Droop R $\mathrm{R}_{1}$ (Hz/p.u.MW) & 2.6 & 2.6 & 2.6 & - & 2.8 & 2.8 & 2.8 & - \\
\hline $\begin{array}{l}\text { Generation Rate } \\
\text { Constraint (p.u./s) }\end{array}$ & 0.00167 & 0.0005 & 0.0167 & - & 0.00167 & 0.0005 & 0.0167 & - \\
\hline $\begin{array}{l}\text { Governor Dead Band } \\
\text { (p.u.) }\end{array}$ & 0.0006 & 0.0006 & 0.0002 & - & 0.0006 & 0.0006 & 0.0002 & - \\
\hline Participation Factor $\alpha$ & 0.3 & 0.5 & 0.2 & - & 0.3 & 0.5 & 0.2 & - \\
\hline $\begin{array}{l}\text { Turbine Reheat } \\
\text { Constant } \mathrm{K}_{\mathrm{rh}}\end{array}$ & - & 0.3 & - & - & - & 0.5 & - & - \\
\hline 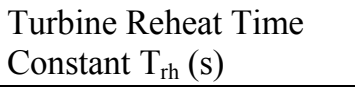 & - & 7 & - & - & - & 10 & - & - \\
\hline $\begin{array}{l}\text { Water Time Constant } \\
\mathrm{T}_{\mathrm{w}}(\mathrm{s})\end{array}$ & - & - & 1 & - & - & - & 2 & - \\
\hline $\begin{array}{l}\text { Transient Droop Time } \\
\text { Constant of the Hydro } \\
\text { Governor } T_{2}(\mathrm{~s})\end{array}$ & - & - & 28.75 & - & - & - & 68.8 & - \\
\hline $\begin{array}{l}\text { Reset Time of Hydro } \\
\text { Governor } T_{r}(s)\end{array}$ & - & - & 5 & - & - & - & 8 & - \\
\hline $\begin{array}{l}\text { Time constant of the } \\
\text { load \& machine } T_{p}(s)\end{array}$ & - & - & - & 4.125 & - & - & - & 7.3 \\
\hline $\begin{array}{l}\text { Gain of the load \& } \\
\text { machine } K_{p} \\
\text { (Hz/p.u.MW) }\end{array}$ & - & - & - & 24.75 & - & - & - & 43.8 \\
\hline $\begin{array}{l}\text { Frequency bias factor } B_{i} \\
\text { (p.u.MW/ Hz) }\end{array}$ & \multicolumn{4}{|c|}{0.425} & \multicolumn{4}{|c|}{0.380} \\
\hline Power Capacity, (MW) & \multicolumn{4}{|c|}{1800} & \multicolumn{4}{|c|}{1200} \\
\hline
\end{tabular}

\section{REFERENCES}

[1] P. Kundur, Power System Stability and Control, New York, USA, McGraw-Hill Education, 1994.

[2] A. Khodabakhshian and M. Edrisi, "A new robust PID load frequency controller," Control Engineering Practice, vol. 16, pp. 10691080, Sep. 2008

[3] M. Zribi, M. Al-Rashed and M. Alrifai, "Adaptive decentralized load frequency control of multi-area power systems," International Journal of Electrical Power \& Energy Systems, vol. 27, pp. 575-583, Oct. 2005.

[4] M. Rahmani and N. Sadati, "Hierarchical optimal robust load frequency control for power systems," IET Generation, Transmission \& Distribution, vol. 6, pp. 303-312, April 2012.

[5] H. Bevrani and T. Hiyama, "On load-frequency regulation with time delays: design and real-time implementation," IEEE Transactions on Energy Conversion, vol. 24, pp. 292-300, March 2009.

[6] C. Zhang, L. Jiang, Q. H. Wu, Y. He and M. Wu, "Delay-dependent robust load frequency control for time delay power systems," IEEE Transactions on Power Systems, vol. 28, pp. 2192-2201, Aug. 2013.

[7] H. Yousef, “Adaptive fuzzy logic load frequency control of multi-area power system,” International Journal of Electrical Power \& Energy Systems, vol. 68, pp. 384-395, June 2015.

[8] P.S.Ponmurugavel and S.M. Ghouse, "Design and modelling of fuzzy and model predictive controllers for STATCOM to enhance transient stability of power system" International Journal of Engineering and Technology, vol. 5, pp. 2609-2619, June-July 2013.

[9] K. R. Sudha and R. Vijaya Santhi, "Load frequency control of an interconnected reheat thermal system using type-2 fuzzy system including SMES units," International Journal of Electrical Power \& Energy Systems, vol. 43, pp. 1383-1392, Dec. 2012. 
[10] D. Rerkpreedapong, A. Hasanovic and A. Feliachi, "Robust load frequency control using genetic algorithms and linear matrix inequalities," IEEE Transactions on Power Systems, vol. 18, pp. 855-861, May 2003.

[11] F. Daneshfar and H. Bevrani, "Multiobjective design of load frequency control using genetic algorithms," International Journal of Electrical Power \& Energy Systems, vol. 42, pp. 257-263, Nov. 2012.

[12] Z. M. Al-Hamouz and H. N. Al-Duwaish, "A new load frequency variable structure controller using genetic algorithms," Electric Power Systems Research, vol. 55, pp. 1-6, July 2000.

[13] H. Golpîra, H. Bevrani and H. Golpîra, "Application of GA optimization for automatic generation control design in an interconnected power system," Energy Conversion and Management, vol. 52, pp. 2247-2255, May 2011.

[14] S. Uma Mageswaran and N.O.Guna Sekhar, "Reactive power contribution of multiple STATCOM using particle swarm optimization," International Journal of Engineering and Technology, vol. 5, pp. 122-126, Feb-March 2013.

[15] P. Bhatt, S. P. Ghoshal and R. Roy, "Load frequency stabilization by coordinated control of Thyristor Controlled Phase Shifters and Superconducting Magnetic Energy Storage for three types of interconnected two-area power systems," International Journal of Electrical Power \& Energy Systems, vol. 32, pp. 1111-1124, Dec. 2010.

[16] K. Zare, M. T. Hagh and J. Morsali, "Effective oscillation damping of an interconnected multi-source power system with automatic generation control and TCSC," International Journal of Electrical Power \& Energy Systems, vol. 65, pp. 220-230, Feb. 2015.

[17] H. Gozde and M. C. Taplamacioglu, "Automatic generation control application with craziness based particle swarm optimization in a thermal power system," International Journal of Electrical Power \& Energy Systems, vol. 33, pp. 8-16, Jan. 2011.

[18] S. Chen, Z. Xu, Y. Tang and S. Lee, "An improved particle swarm optimization algorithm based on centroid and exponential inertia weight," Mathematical Problems in Engineering, vol. 2014, pp. 1-14, Dec. 2014.

[19] W. U. Jianxin, L. Wenzhi, Z. Weiguo and L. I. Qiang, "Exponential type adaptive inertia weighted particle swarm optimization algorithm," in Proc. of Second International Conference on Genetic and Evolutionary Computing, pp. 79-82, Sep. 2008.

[20] M. Eslami, H. Shareef, A. Mohamed and M. Khajehzadeh, "An efficient particle swarm optimization technique with chaotic sequence for optimal tuning and placement of PSS in power system," International Journal of Electrical Power \& Energy Systems, vol. 43, pp. 1467-1478, Feb. 2012.

[21] A. H. Gandomi, G. J. Yun, Xin-She Yang and S. Talatahari, "Chaos-enhanced accelerated particle swarm optimization," Communications in Nonlinear Science and Numerical Simulation, vol. 18, pp. 327-340, Feb. 2013.

[22] Y. He, S. Yang and Q. Xu, "Short-term cascaded hydroelectric system scheduling based on chaotic particle swarm optimization using improved logistic map," Communications in Nonlinear Science and Numerical Simulation, vol. 18, pp. 1746-1756, July 2013.

[23] H. Gozde, M. C. Taplamacioglu and İ. Kocaarslan, "Comparative performance analysis of artificial bee colony algorithm in automatic generation control for interconnected reheat thermal power system," International Journal of Electrical Power \& Energy Systems, vol. 42, pp. 167-178, Nov. 2012.

[24] A. K. Barisal, "Comparative performance analysis of teaching learning based optimization for automatic load frequency control of multi source power system,” International Journal of Electrical Power \& Energy Systems, vol. 66, pp. 67-77, March 2015.

[25] M. Raju, L. C. Saikia and N. Sinha, "Automatic generation control of a multi-area system using ant lion optimizer algorithm based PID plus second order derivative controller," International Journal of Electrical Power \& Energy Systems, vol. 80, pp. 52-63, Sep. 2016.

[26] P. Dash, L. C. Saikia and and N. Sinha, "Automatic generation control of multi area thermal system using bat algorithm optimized PD-PID cascade controller," International Journal of Electrical Power \& Energy Systems, vol. 68, pp. 364-372, Jun 2015.

[27] P. Dahiya, V. Sharma and R. Naresh, "Solution approach to automatic generation control problem using hybridized gravitational search algorithm optimized PID and FOPID controllers," Advances in Electrical and Computer Engineering, vol. 15, pp. 23-34, 2015.

[28] S. Panda, B. Mohanty, and P. K. Hota, "Hybrid BFOA-PSO algorithm for automatic generation control of linear and nonlinear interconnected power systems," Applied Soft Computing, vol. 13, pp. 4718-4730, Dec. 2013.

[29] R. K. Sahu, S. Panda, S. Padhan, "A hybrid firefly algorithm and pattern search technique for automatic generation control of multi area power systems," International Journal of Electrical Power \& Energy Systems, vol. 64, pp. 9-23, Jan. 2015.

\section{AUTHOR PROFILE}

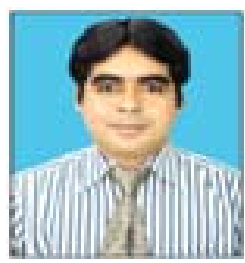

Santigopal Pain was born on $9^{\text {th }}$ April 1976 in Bankura, West Bengal, India. He received his B.E.E. degree from North Bengal University and M.E.E. degree from Jadavpur University, India, in 1999 and 2003 respectively. He has two years Industrial Experience and 12 years teaching experience. He continued his teaching profession in BUIE, Bankura, BCREC, Durgapur, India. He is currently working toward the PhD degree in NIT Durgapur, India. His research interest includes application of soft-computing techniques in Power System and Control System Engineering.

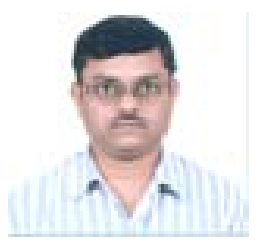

Parimal Acharjee was born on $22^{\text {nd }}$ October, 1973 in Howrah, West Bengal, India. He passed B.E.E. from North Bengal University, M.E.E. and PhD. from Jadavpur University, India, Post Doc. from New Mexico State University (NMSU), New Mexico. He has three years Industrial Experience and 14 years teaching experience. He continued his teaching profession in MCKVIE, Howrah, BPPIMT, Kolkata, NIT Silchar, India. He is presently working in NIT Durgapur, India as an Associate Professor. He conducted AICTE and TEQIP sponsored different courses, gave invitee talks to Engineering colleges, chaired national \& international conferences. He received Indo-US research fellowship and research fund from DST, New Delhi. His current research interest is the application of soft-computing techniques in various power system problems, FACTS Devices, Smart Grid. 